\title{
Gastroesophageal Reflux Disease
}

National Cancer Institute

\section{Source}

National Cancer Institute. Gastroesophageal Reflux Disease. NCI Thesaurus. Code C26781.

A chronic disorder characterized by reflux of the gastric and/or duodenal contents into the distal esophagus. It is usually caused by incompetence of the lower esophageal sphincter. Symptoms include heartburn and acid indigestion. It may cause injury to the esophageal mucosa. 